\title{
Planar Oxygen Sensors for Non Invasive Imaging in Experimental Biology
}

\author{
Henning Tschiersch ${ }^{1}$, Gregor Liebsch², Achim Stangelmayer², \\ Ljudmilla Borisjuk ${ }^{1}$ and Hardy Rolletschek ${ }^{1}$ \\ ${ }^{1}$ Institut für Pflanzengenetik und \\ Kulturpflanzenforschung (IPK), Gatersleben, \\ ${ }^{2}$ PreSens Precision Sensing GmbH, Regensburg,
}

Germany

\section{Introduction}

The presence of molecular oxygen is a sine qua non for aerobic metabolism. In both plant and animal mitochondria, it acts as the terminal electron acceptor for oxidative phosphorylation occurring during cellular respiration, and is necessary for the generation of ATP, the common energy currency within the living cell (Atkinson, 1977; Cooper, 2000). It is the major by-product of photosynthesis in which plant biomass is accumulated by the conversion of carbon dioxide into polymeric compounds. Since respiration and photosynthesis are so fundamental to life on earth, an understanding of the mechanisms underlying oxygen consumption, production and homoeostasis has become a significant field of both biological and biotechnological research (Volkmer et al., 2009).

Oxygen (micro-) sensors, which are widely used in the life sciences, are designed to provide a precise measurement of the concentration of oxygen within a localized region of a tissue or an organ (Borisjuk \& Rolletschek, 2009). Most of these devices have been based on miniaturized Clark-type electrodes (Revsbech \& Jørgensen, 1986), in which oxygen diffuses into the sensor via a permeable membrane, following which its reduction at the cathode generates a measurable electrical current. This approach can deliver a spatial resolution at the low $\mu \mathrm{m}$ scale. Increasingly this technology is being replaced by optical oxygen microsensors (micro-optodes) based on fibre optic materials (Klimant et al., 1995; Rolletschek et al., 2009), in which the concentration is assessed in tapered glass fibres of tip size $\sim 50 \mu \mathrm{m}$ via the dynamic quenching of a luminophore. This approach enjoys several advantages over the electrochemical detection system, as detailed elsewhere (Kühl \& Polerecky, 2008; Rolletschek et al., 2009).

Importantly, microsensor-based approaches are invasive, which means that a given biological sample cannot be readily studied over a prolonged time period. Furthermore, the internal structure of most biological samples is far from homogeneous, with complex compartmentation being the norm. As a result, whole tissue measurements can only reflect the mean performance of a tissue, and cannot report variation between distinct compartments. This loss of richness compromises the value of such data for elucidating the biology of the tissue as a whole. At best, conventional sensor systems assess oxygen 
concentrations across a transect, leaving its two dimensional distribution unknown. Lifting this limitation requires the development of a planar sensor.

Here, we present a novel oxygen sensing approach, in which image processing has been combined with optical sensor technology. The optical sensor foil (i.e. the planar optode) attached to the surface of the sample translates the oxygen signal into a light signal, which is then captured and interpreted pixel by pixel by a digital camera. Since a single image captures an array of sensor points, the system permits an instantaneous two-dimensional mapping of oxygen distribution. While some analagous approaches have already been described in the literature (Liebsch et al., 2000; Glud et al., 2005; Kühl \& Polerecky, 2008), the system we describe here represents a significant improvement with respect to spatial resolution, handling and image processing, and eventually ease of use. Two applications of the system are described in some detail: the first involves a respiring (oxygen consuming) root of oilseed rape (Brassica napus), and the second a photosynthetically active (oxygen generating) leaf of Cabomba caroliniana, an aquatic perennial herbaceous plant. In both, marked oxygen gradients were detected across both time and space. In combination with the use of specific inhibitors, the planar sensor system can be expected to permit a spatially well resolved analysis of respiration or photosynthesis. We conclude that the new planar sensor setup provides fascinating opportunities for research in all areas of life sciences.

\section{Planar oxygen sensors - design, calibration and applications}

The following chapters provide an overview on (i) the technical features of the novel planar sensor setup, and (ii) the possibilities for its use in plant biology, in particular to study respiration (oxygen consumption) and photosynthesis (oxygen production).

\subsection{Experimental design for life time imaging of oxygen}

Digital revolution in photography induced a giant trend towards capturing images and creating movies of nearly everything one can think of. Beside scientific and industrial cameras the market of consumer imaging devices is constantly growing and continually new products are launched showing increased resolution while being miniaturized. The enhancement of image quality and downsizing affects all market segments of consumer cameras, high-quality SLR cameras as well as low-tech webcams and mobile phone cameras. As a result, the use of such consumer devices is also of increasing interest in the field of opto-chemical sensing where the response of a fluorescent sensor is recorded in order to measure chemical analytes. Typically, for this application fairly bulky and sophisticated camera systems (Holst et al., 1998; Schröder et al., 2007; Kühl \& Polerecky, 2008) are used which support time resolved measurement. Measuring a lifetime dependent parameter is generally preferred because of the favourable accuracy due to suppressing common interferences including heterogeneous lightfield or sample coloration and auto-fluorescence allowing even transparent sensor foils (Holst et al., 2001). This is not possible if using even high-tech standard consumer cameras which allow ratiometric calibration schemes at best. However, beside the restriction of transparent sensors ratiometric imaging has proved to be also an excellent solution for measuring analyte contents of a sample quantitatively and two dimensionally (Wang et al., 2008). Then, it depends on the sample target and analytical problem if the possibility of miniaturisation and mobility overcompensates the restriction. Especially in biological application fields of imaging with fluorescent optical sensors it is desirable to use compact devices which are close to pocket size and can easily be taken to 
the place of measurement. As a result, complex biological systems are not disturbed and can be measured "as is" in their natural environment or green house. New reports address the topic of applying portable consumer technology by using SLR cameras (Wang et al., 2010) or even mobile phones (Filippini \& Lundstrom, 2006) with the side-effect of substantially reducing the costs for imaging devices at the same time. However, in these solutions the question about suitable optical filters, macro lense and light source combinations is not sufficiently solved. Especially a micrometer resolution is indispensable if investigating biological processes of plant seeds, embryos, collenchyma or rhizospheres. Also in other medical and biotechnical applications a high resolution is needed including monitoring phase transitions in aquatic biology, mini bioreactors, tissue engineering and skin microcirculation. Therefore, we developed the idea of using consumer camera technology further and identified a type which fits perfectly to the demands of fluorescent optical imaging: the USB microscope. The results presented here were measured with a prototype of new imaging product series "VisiSens" (PreSens GmbH, Regensburg, Germany).

The market of USB microscopes is allocated to many types showing huge differences in image quality. We based our development on a current high-end USB microscope with good sensitivity and image quality and improved it for imaging fluorescence-optical sensors by integrating an optic block with high quality LED PCB and optical filters. Figure 1 shows a solid (left panel) and a transparent (middle panel) technical drawing of the measurement head, showing its compactness and the arrangement of the respective components. The three images beside show millimeter paper measured with different magnification settings. Maximum magnification is approximately 200-fold where the field of view is $\sim 2.5 \times 2.0 \mathrm{~mm}$.

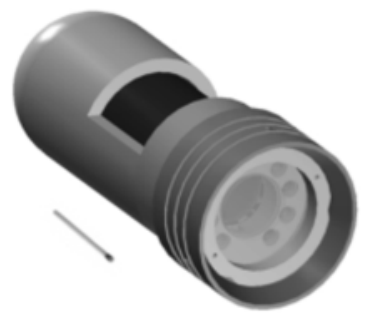

a

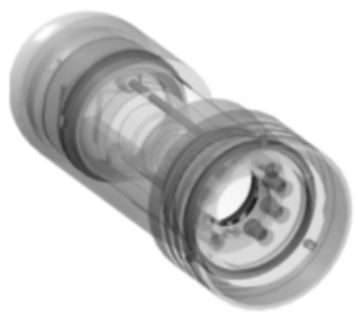

b

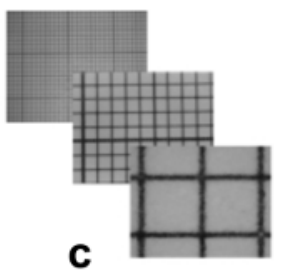

C

Fig. 1. (a) Solid and (b) transparent technical drawing of the compact measurement head incorporating a USB-microscope for imaging fluorescent sensor foils. Camera and light source are powered via standard USB connector. (c) Images of millimeter paper demonstrating the magnification up to 200 -fold.

Figure 2 shows an explosion drawing of the USB microscope where the components are addressed in detail. The all-aluminium detector head (a) integrates a color RGB CMOS chip (b), a microscope lense (c) with manual focus, 8 blue emitting LEDs (i) which are driven by a printed circuit board (PCB) (g) and aligned in an aluminium block (h) and optical filters for light diffusion (j), excitation ( $\mathrm{k}$ ) and emission (l). The up to 200 -fold magnified images are recorded with a 1.3 megapixel $(1280 \times 1024)$ color chip which results in more than 300,000 independent sensing points $(=$ pixel) for the respective sensor response (i.e. color channel of the RGB chip). Maximum spatial image resolution is $\sim 2.5 \mathrm{~mm}$ per 1280 pixel $(\sim 2 \mu \mathrm{m}$ per 
pixel). Maximum spatial sensor resolution depends on the sensor used and is typically $\sim 25$ to $100 \mu \mathrm{m}$. Power supply of the camera and the LED light source is provided via the standard USB connector which makes the system laptop compatible and a portable device. The dimensions of the detection head are $10 \mathrm{~cm}$ in length and $3.8 \mathrm{~cm}$ in diameter, the working distance is typically from 1 to $5 \mathrm{~cm}$. The camera can be used free hand or mounted to a stand.

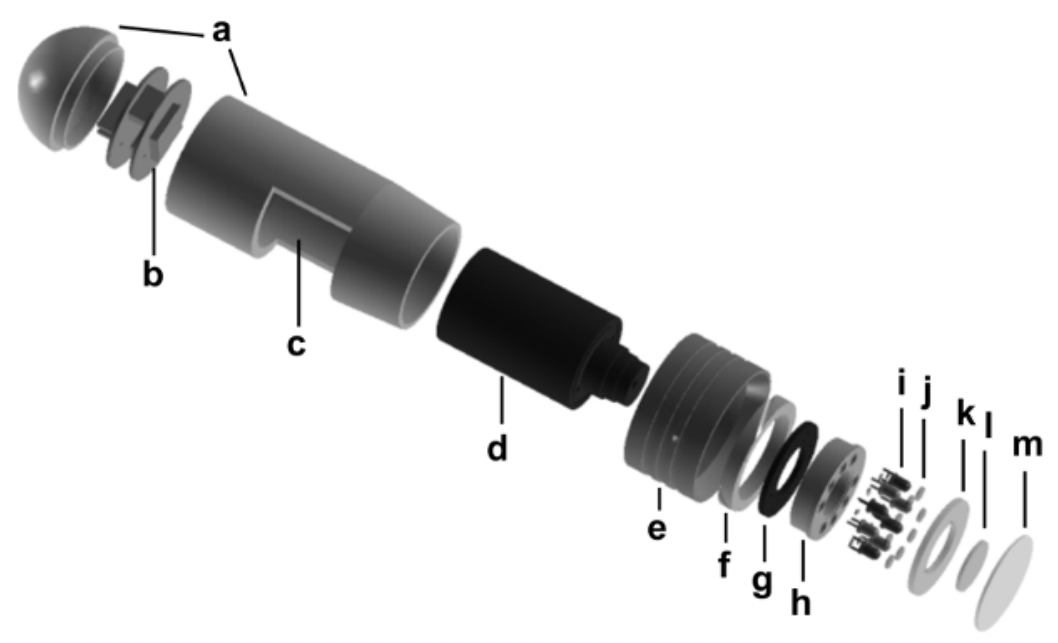

Fig. 2. Explosion drawing of the PreSens USB-microscope "VisiSens" optimized for imaging of fluorescencent sensor foils: (a) aluminium housing, (b) RGB CMOS-chip, (c) opening for manual focus, (d) microscope lense, (e) filter tube, (f) mounting and adjustment ring (g) transmitter PCB, (h) LED reflector block, (i) LEDs, (j) diffusor, (k) short pass excitation filter, (l) long pass emission filter and (m) sapphire glass.

For the measurement the imaging system uses flexible sensor foils which allow two dimensional recording of oxygen distributions in aqueous phase over an area typically ranging from $5 \times 5 \mathrm{~mm}^{2}$ up to $40 \times 40 \mathrm{~mm}^{2}$. The planar sensors consist of an oxygen sensitive dye and a reference dye which are immobilized in an oxygen permeable polymer matrix and fixed on a transparent polyester support and overlaid with a white oxygen transparent layer for optical isolation. We used a PreSens sensor foil which is not described here but similar to that described in detail by Wang et al., (2010).

During the measurement the sensitive layer is in contact with the sample and the fluorescence is measured from the backside. Every single indicator dye molecule is interacting independently with oxygen in the form that the red fluorescence of the sensitive dye is dynamically quenched. This means that the energy of the excited dye is transferred to the oxygen molecule by collision (see Fig. 3) and consequently the intensity of the sensitive dye is reduced with increasing oxygen content of the sample.

The reference dye, however, is not affected by oxygen and shows constantly a green light signal. The working range of the oxygen sensor covers the typical biological range from 0 to $100 \%$ air saturation (corresponding to $6.04 \mathrm{~mL}$ of oxygen per liter freshwater at $25^{\circ} \mathrm{C}$ and 101.3 $\mathrm{kPa}$ standard atmosphere). The sensors can be shaped to any desired geometry using a scissor. 


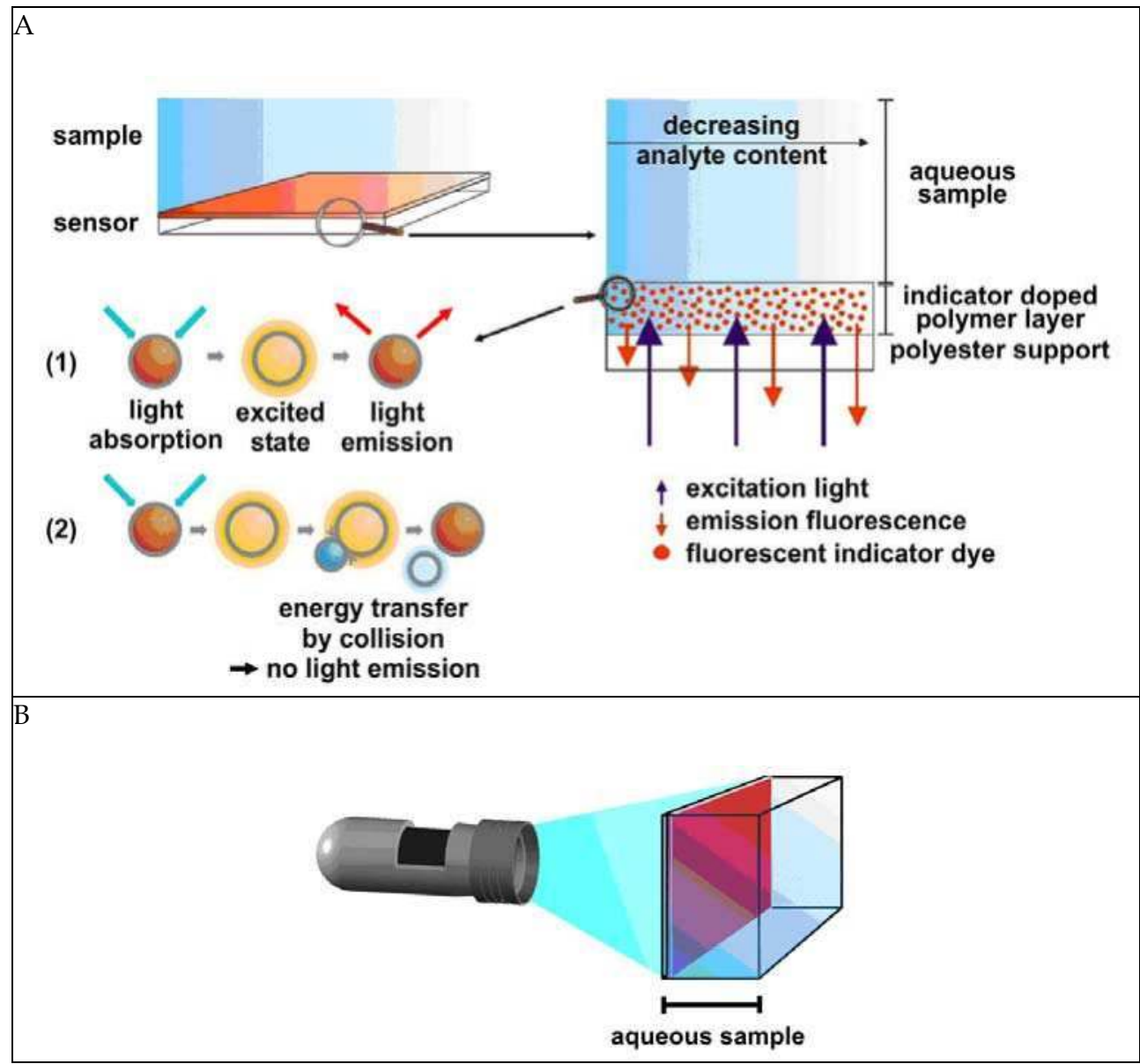

Fig. 3. (A) Schematic of the sensor foil and principle of dynamic fluorescence quenching. The sensor responds to oxygen by passing the energy of an excited state dye via collision to the oxygen molecule. This results in fluorescence quenching with increasing oxygen content of the sample. (B) Measurement set-up. The sensor consists of an indicator doped polymer layer which is fixed on a transparent polyester support. During the measurement the sensor has to be in direct contact with the sample. The sensor response is measured from outside through a transparent window of the respective vessel.

For quantitative evaluation of the sensor response we applied a ratiometric calibration scheme. The sensitive dye and reference dye are excited with the identical light source at the same time but emit at different bands of wavelength. In our case, both dyes are excited with blue light and while the sensitive dye emits red light, the reference emits green light. We selected dyes whose emission bands of wavelength meet exactly the red and green channel sensitivity of our color RGB chip. This enables to obtain the green reference information independently from the red sensor information within a single image at the same time. A quantitative evaluation is done by rationing the red and green channel of the RGB image in 
order to reference out the main interferences of intensity based measurements namely inhomogeneous light field and dye concentration including varying sensor layer thickness. The respective oxygen content is computed from the ratio applying a calibration function which was derived from measuring the sensor response at known oxygen concentrations in a chamber (Figure 4).

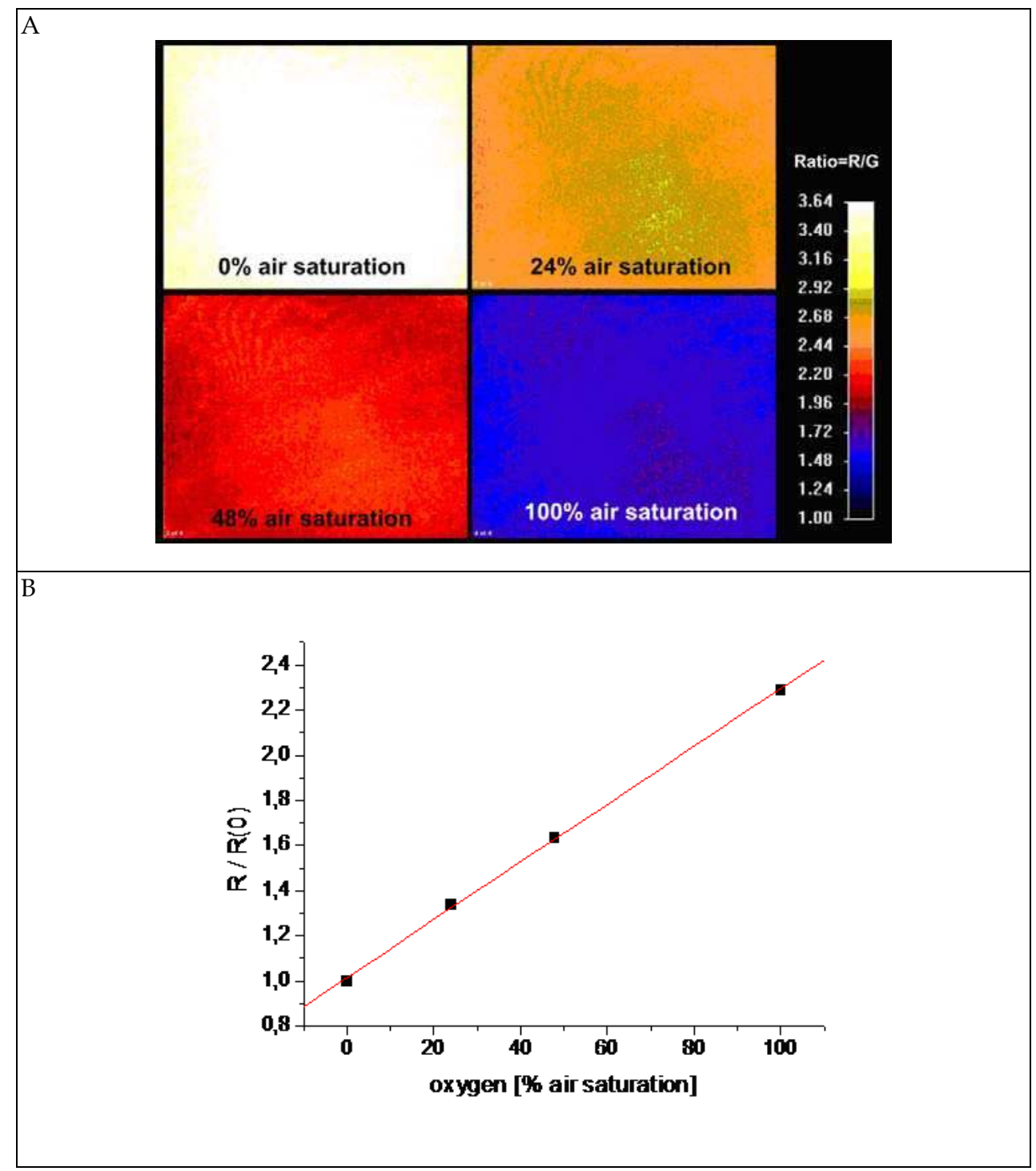

Fig. 4. (A) Calibration Images and data. The sensor was exposed to different oxygen gas mixtures and the response was imaged. (B) The Stern-Vollmer plot leads to a linear relation which was used for calculating the respective oxygen contents of the measurement images. 


\subsection{Application of planar optical sensors for oxygen measurements on plants}

Unlike animals, plants are both producers and consumers of oxygen via photosynthesis and cellular respiration, respectively. Plant leaves, stems and seed tissues generally possess chloroplasts, producing oxygen under illumination ((Borisjuk and Rolletschek, 2009; Tschiersch et al., 2011) whereas roots are a typical example of non-green tissues. Their oxygen homoeostasis and exchange capabilities depend on the developmental state (age), several tissue characteristics (e.g. cuticula) as well as environmental conditions (e.g. temperature) (Armstrong et al., 1994, 2009). In particular, the complex anatomy of tissues often hampers oxygen diffusion, thereby causing steep diffusion gradients and local oxygen deficiencies.

Planar oxygen sensors are an alternative to conventional microsensor-based techniques, and allow to viualize the oxygen dynamics between tissues and surrounding media. Here, we demonstrate the applicability of the planar sensor system to study oxygen dynamics in two plant models: (i) the respirating $\left(\mathrm{O}_{2}\right.$-consuming) root system of the crop plant oilseed rape (Brassica napus), and (ii) the photosynthetically active $\left(\mathrm{O}_{2}\right.$-producing) leaf of the water plant Cabomba caroliniana.

\subsubsection{Imaging of oxygen consumption in living plant roots}

Several contrasting plant species, that differ in their relative growth rates (herbs, grasses, shrubs and trees), possess respiration rates in a relative narrow range between 20 and 52 nmol oxygen (g DW) $)^{-1} \mathrm{~s}^{-1}$ (Loveys et al., 2003). Similar values were reported for roots of crop plant seedlings using clark-type electrodes (Tab. 1). For roots of oilseed rape seedlings we measured mean respiration rates of $\sim 79 \mathrm{nmol}$ oxygen $(\mathrm{g} \mathrm{DW})^{-1} \mathrm{~s}^{-1}$ (own unpublished data).

\begin{tabular}{|c|c|c|}
\hline Species & $\begin{array}{c}\text { Root respiration rate } \\
{\left[\mathrm{nmol} \mathrm{O}_{2}(\mathrm{gDW})^{-1} \mathrm{~s}^{-1}\right]}\end{array}$ & References \\
\hline Oilseed rape (Brassica napus) & 79.3 & this study \\
\hline Barley (Hordeum vulgare) & 16.2 & Bloom et al., 1992 \\
\hline Wheat (Triticum aestivum) & 64.0 & Kurimoto et al., 2004 \\
\hline Rice (Oryza sativa) & 39.1 & Kurimoto et al., 2004 \\
\hline Corn (Zea mays) & 56.7 & Hejl \& Koster, 2004 \\
\hline Potato (Solanum tuberosum) & 14.8 & Bouma et al., 1996 \\
\hline $\begin{array}{c}\text { Tomato (Solanum } \\
\text { lycopersicum) }\end{array}$ & 15.8 & Hadas \& Okon, 1987 \\
\hline Pea (Pisum sativum) & 69.2 & DeVisser et al., 1986 \\
\hline Soybean (Glycine max.) & 67.5 & Millar et al., 1998 \\
\hline
\end{tabular}

Table 1. Root respiration rates of various crop plants

Using the planar oxygen sensor we here aimed to visualize quantitatively the oxygen consumption of intact roots. For this purpose oilseed rape was grown on $0.9 \%$ Difco-agar for 14 days. For the measurement the root segments of seedlings were covered with the transparent sensor foil. The use of transparent foils is of special importance because it allows the alignment between the sample structure and the measured oxygen distribution. The sample was enclosed by an incubation chamber to limit oxygen diffusion from the outside. This custom-made system allowed the combined imaging of the root (Fig. 5a) and the oxygen concentration (Fig. 5b). In our experiment, the oxygen distribution in the sample was followed over six hours with measuring points every $15 \mathrm{~min}$. Based on the decline in oxygen concentration over time, the respiration rate of the central root zone was calculated 
as $0.015 \%$ air saturation min $^{-1}$, which corresponds to $\sim 12.5 \mu \mathrm{mol}$ oxygen $\mathrm{h}^{-1}$. The final image of oxygen distribution in Fig. $5 b$ demonstrates that oxygen consumption of the root system can be mapped for distinct root regions with sub-millimetre resolution using the planar sensor setup. It should be noted that the use of thin sensor foils and incubation chambers is preferable, because this reduces diffusive smearing of the spatial oxygen distribution, which otherwise can mask the true oxygen dynamics as well as its gradients. Thus, it allows maximizing the spatial resolution in oxygen mapping.
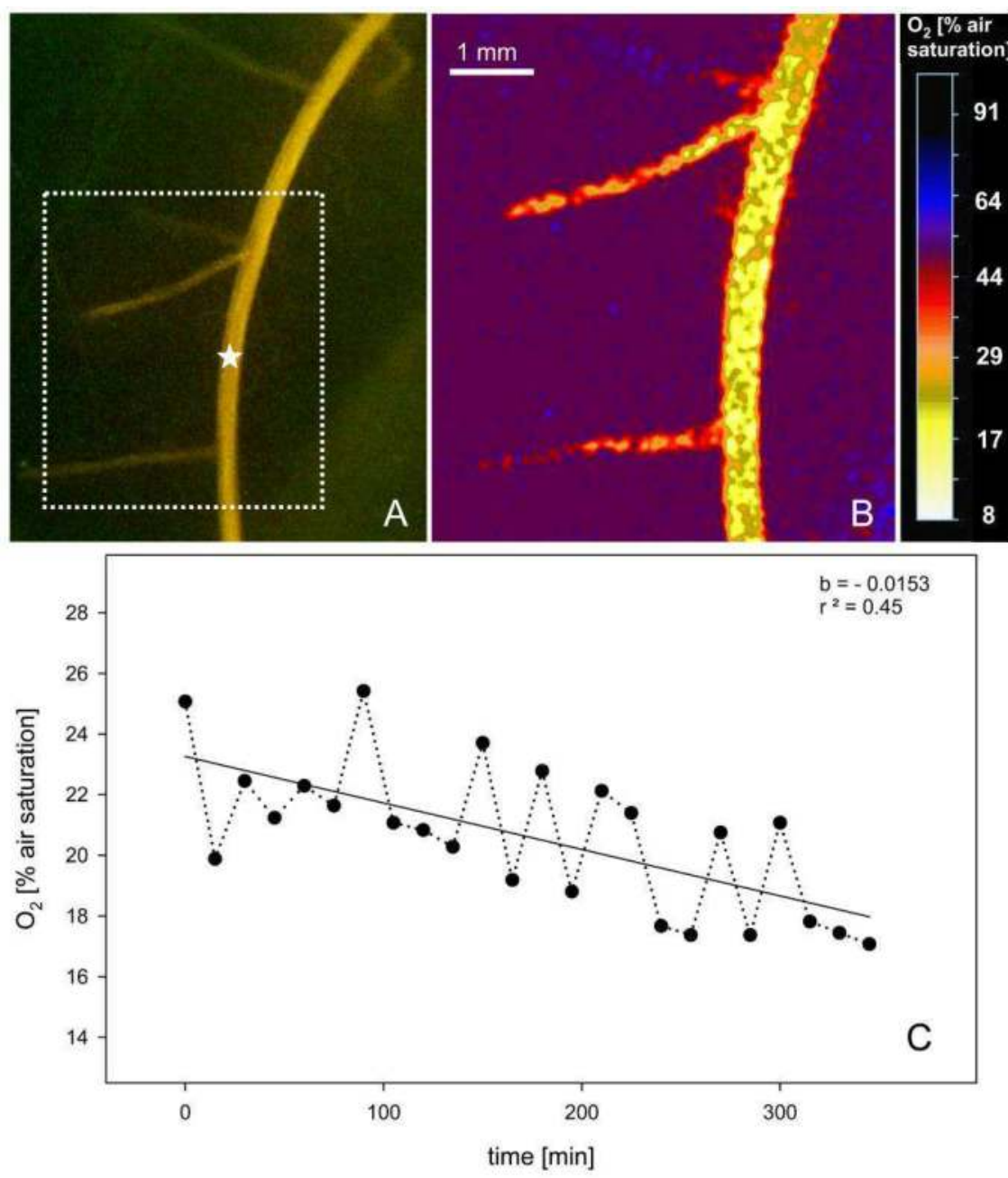

Fig. 5. Imaging of oxygen consumption for roots of oilseed rape. (A) Picture of the root system; the square indicates the area where oxygen imaging was applied. (B) Image of oxygen distribution after $6 \mathrm{~h}$ of dark incubation. (C) Time course of oxygen concentration measured within the main root area (region indicated by the star in (A)) 


\subsubsection{Monitoring of oxygen dynamics in photosynthetically-active leaves}

The water plant Cabomba caroliniana is known as a classical object in photosynthesis research (Smith, 1936; Kok, 1949). Traditionally, fronds of Cabomba were used in the classroom to demonstrate bubble formation (photosynthetic oxygen evolution) upon illumination. Cabomba leaves freshly collected from surface waters show a photosynthetic rate at light saturation of about $2.5 \mu \mathrm{mol} \mathrm{CO}$ consumed $(\mathrm{mg} \mathrm{Chl})^{-1} \mathrm{~h}^{-1}$ and a respiratory rate of 2-3 $\mu \mathrm{mol}$ $\mathrm{CO}_{2}$ evolved (mg Chl)-1 $\mathrm{h}^{-1}$ (Van et al., 1976). In a more recent study, respiration rates of up to $30 \mu \mathrm{mol} \mathrm{O}_{2}\left(\mathrm{~g} \mathrm{DW}^{-1} \mathrm{~h}^{-1}\right.$ were reported (Penuelas et al., 1988).

Here, we aimed to visualize both consumption and production of oxygen in the Cabomba leaf. For this purpose, one Cabomba frond was covered with the sensor foil, and enclosed in the incubation chamber (restricting oxygen diffusion from the exterior). This custom-made system allowed the combined imaging of leaf structure and oxygen concentration. Figure 6a shows a picture of the Cabomba leaf. Its incubation under non-lit conditions for only $30 \mathrm{~min}$ led to a remarkable decrease in oxygen concentration, which was attributable to cellular respiration. The overlay of the color image and the sensor response image in Fig. $6 \mathrm{~b}$ demonstrates that this decrease co-localised with the characteristic leaf shape of the plant. The oxygen level declined to $\sim 13 \%$ of air saturation after 60 min under non-lit conditions (Fig. 6c). This indicates a substantial respiratory activity of Cabomba leaves. Upon illumination $\left(15 \mu \mathrm{mol}\right.$ photons $\left.\mathrm{m}^{-2} \mathrm{~s}^{-1}\right)$, a quick increase in oxygen concentration became apparent (Fig. 6c), indicating a strong oxygen production by the leaf. This activity could again be clearly aligned to the leaf shape (Fig. 6d versus 6e).

We suggest that the increase in oxygen concentration under lit conditions was caused by leaf photosynthesis. To prove this suggestion, we performed a similar light/dark experiment with Cabomba leaves in the presence of the photosynthesis inhibitor 3-(3,4Dichlorophenyl)-1,1-dimethylurea (DCMU). The addition of $20 \mu \mathrm{M}$ DCMU completely abolished the light-dependent oxygen production of the leaf (Fig. 6c). This clearly demonstrates that the light-induced increase in oxygen levels is due to photosynthesis.

The differences between the oxygen exchange rates in darkness and light were remarkable, and demonstrate the high photosynthetic capacity of Cabomba caroliniana even under low light supply. The imaging experiment revealed that (i) the oxygen production under low light $\left(15 \mu \mathrm{mol}\right.$ photons $\left.\mathrm{m}^{-2} \mathrm{~s}^{-1}\right)$ fully compensated dark respiration, and (ii) the oxygen evolution rate in the light was five times higher as compared to the oxygen consumption rate in the dark. This result was confirmed by conventional microsensor-based analysis (optical oxygen sensor SP-PSt3 connected to Fibox3 oxygen meter; PreSens Sensing GmbH, Germany). Under non-lit conditions, a respiration rate of $26.1 \mu \mathrm{mol} \mathrm{O} 2(\mathrm{~g} \mathrm{DW})^{-1} \mathrm{~h}^{-1}$ was measured for Cabomba leaves. Under lit conditions $\left(<10 \mu \mathrm{mol}\right.$ photons $\left.\mathrm{m}^{-2} \mathrm{~s}^{-1}\right)$, the photosynthetic oxygen production was sufficient to fully compensate oxygen consumption by respiration (own unpublished data).

The planar sensor system can be used to monitor fast responses of leaves to dark/light switches. Figure 7 displays in detail the differential effect of light versus darkness on the oxygen exchange of the Cabomba leaf. Within a few minutes clear changes in oxygen concentration could be monitored in darkness. Extended incubation under dark resulted on the one hand in a stronger decrease in oxygen concentration and on the other hand in a smearing of the sensor signal due to the diffusion of oxygen (Fig. 7, left panels). Upon start of illumination $\left(15 \mu \mathrm{mol}\right.$ photons $\left.\mathrm{m}^{-2} \mathrm{~s}^{-1}\right)$, the fluorescence signal declines steadily, which indicates the photosynthetic oxygen release. We conclude that the planar sensor system can perform both spatial and temporal oxygen monitoring. 

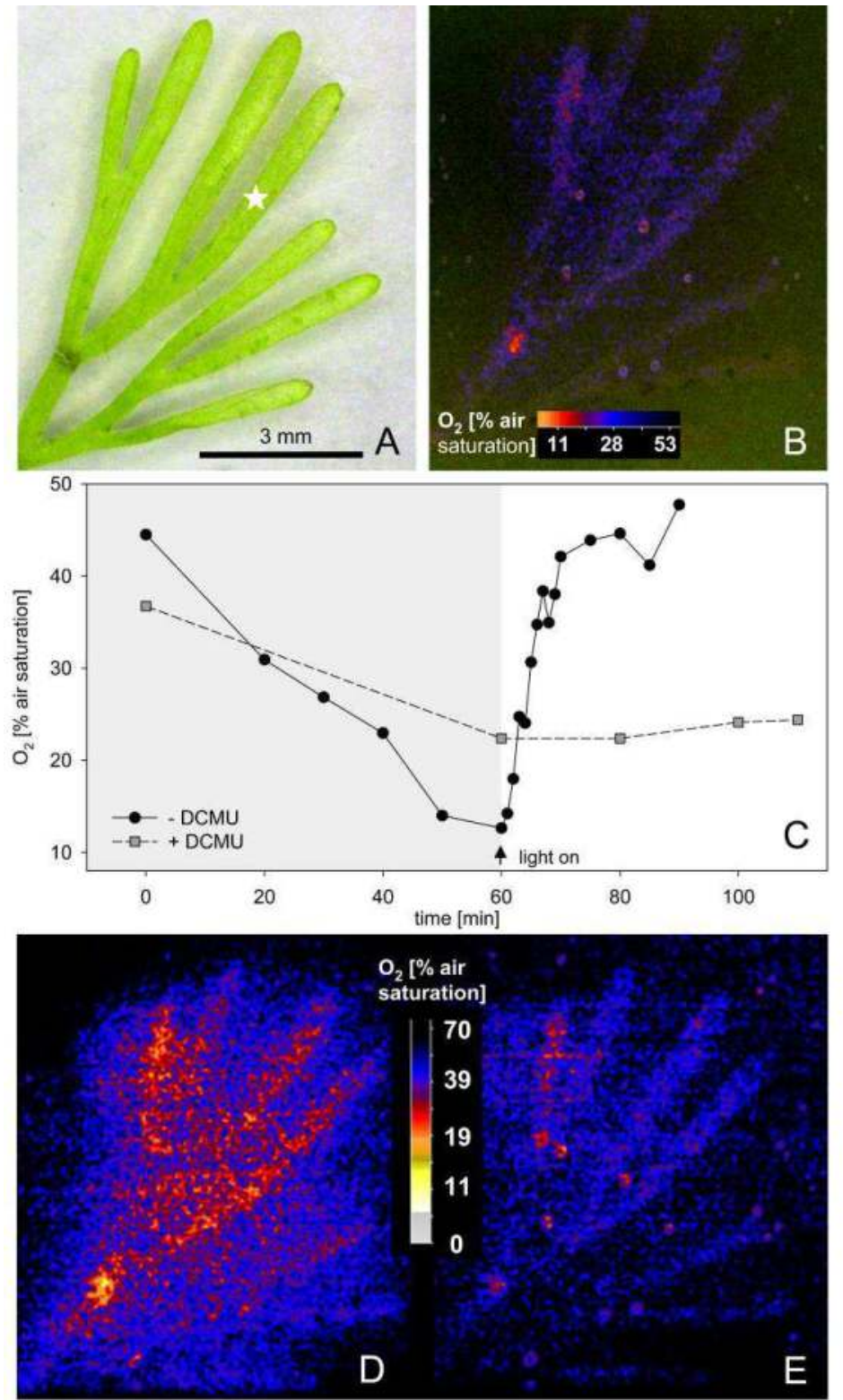

Fig. 6. Imaging of oxygen exchange by the leaf of Cabomba caroliniana. (A) Color image of the leaf. (B) Superimposed images of leaf and oxygen distribution after 20 min dark incubation. (C) Time course of oxygen dynamics of leaf with and without addition of DCMU; analysed region corresponds to $1.4 \mathrm{~mm}^{2}$ leaf area marked with a star in (A). (D) Image of oxygen distribution after $30 \mathrm{~min}$ dark incubation. (E) Image of oxygen distribution after $30 \mathrm{~min}$ light incubation $\left(15 \mu \mathrm{mol}\right.$ photons $\left.\mathrm{m}^{-2} \mathrm{~s}^{-1}\right)$ subsequent to dark incubation. 


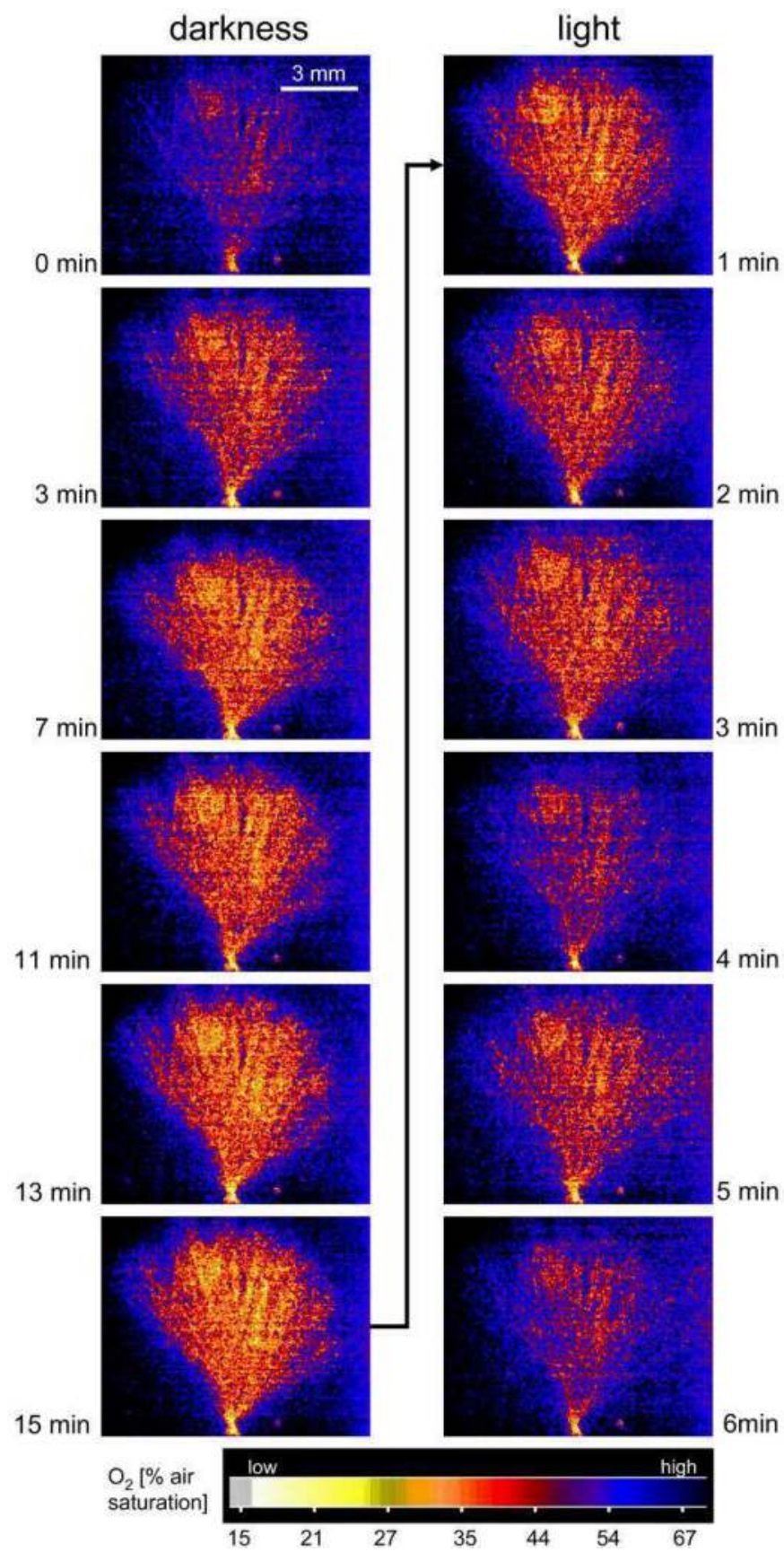

Fig. 7. Monitoring of oxygen dynamics of a Cabomba caroliniana leaf during $15 \mathrm{~min}$ of dark incubation and the subsequent light phase $\left(15 \mu \mathrm{mol}\right.$ photons $\left.\mathrm{m}^{-2} \mathrm{~s}^{-1}\right)$. 


\section{Prospects for planar oxygen sensing}

Above data clearly illustrate the major advantage of planar oxygen sensing as a noninvasive imaging technique. For the first time, rates of oxygen production and consumption could be spatially resolved and visualized. The acquired color-coded oxygen maps are quantitative and have a resolution in the sub-millimetre range. In this way, dynamic changes in oxygen concentration within the complex root (leaf) system of a plant and its surrounding media can be studied. This non-invasive approach will allow investigating mechanisms of cellular growth and interactions among organisms and their environment. Although not studied here, the planar oxygen sensor system will be of high significance in other research areas like biotechnology or medicine. For example, documenting the oxygen dynamics during cell infection and cancerogenesis could help identify specific drug targets to slow or stop the uncontrolled growth of cancer cells (Babilas et al., 2005).

Currently, planar sensors have been developed to specifically detect oxygen, carbon dioxide or $\mathrm{pH}$. It is also conceivable that planar sensor foils have multi-analyte properties. These sensors will combine an oxygen sensitive dye (and its reference dye) with dyes specific for other analytes. In this way, several analytes can be quantitatively visualized in single experiments.

\section{Acknowledgment}

We acknowledge funding by the Bundesministerium für Wirtschaft und Technologie within the framework of Zentrales Innovationsprogramm Mittelstand (ZIM). We also wish to thank Steffen Wagner for excellent technical assistance.

\section{References}

Armstrong, W., Strange, M.E., Cringle, S. \& Beckett, P.M. (1994). Microelectrode and modelling study of oxygen distribution in roots. Annals of Botany, Vol.74, No.3, (September 1994), pp. 287-299, ISSN 0305-7364

Armstrong, W., Webb, T., Darwent, M. \& Beckett, P.M. (2009). Measuring and interpreting respiratory critical oxygen pressures in roots. Annals of Botany, Vol.103, No.2, (January 1994), pp. 281-293, ISSN 0305-7364

Atkinson, D.E. (ed.). (1977). Cellular energy metabolism and its regulation. Academic Press, ISBN 0120661500 , New York, USA

Babilas, P., Liebsch, G., Schacht, V., Klimant, I., Wolfbeis, O.S., Szeimies, R.M. \& Abels, C. (2005). In vivo phosphorescence imaging of $\mathrm{pO}_{2}$ using planar oxygen sensors. Microcirculation, Vol.12, No.6, (September 2005), pp. 477-487, ISSN 1073-9688

Bloom, A.J., Sukrapanna, S.S. \& Warner, R.L. (1992). Root respiration associated with ammonium ore nitrate absorption and assimilation by barley. Plant Physiology, Vol.99, No.4, (August 1992), pp. 1294-1301, ISSN 0032-0889

Borisjuk, L. \& Rolletschek, H. (2009). The oxygen status of the developing seed. New Phytologist, Vol.182, No.1, (April 2009), pp. 17-30, ISSN 0028-646X

Bouma, T.J., Broekhuysen, A.G.M. \& Veen, B.W. (1996). Analysis of root respiration of Solanum tuberosum as related to growth, ion uptake and maintenance of biomass. Plant Physiology and Biochemistry, Vol. 34, No.6, (June 1996), pp. 795-806, ISSN 0981-9428 
Cooper, G.M. (2000). The Cell - A Molecular Approach (2nd edition), Sinauer Associates, ISBN-10: 0-87893-106-6, Sunderland (MA),USA

DeVisser, R., Brouwer, K.S. \& Posthuma, F. (1986). Alternative path mediated ATP-synthesis in roots of Pisum sativum upon nitrogen supply. Plant Physiology, Vol.80, No.2, (February 1986), pp. 295-300, ISSN 0032-0889

Filippini, D. \& Lundstrom, I. (2006). Method and system for chemical or biochemical analysis of a target analyte in a target environment. US Pat. 7,092,089.

Glud, R.N., Wenzhöfer, F., Tengberg, A., Middelboe, M., Oguri, K. \& Kitazato, H. (2005). Distribution of oxygen in surface sediments from central Sagami Bay, Japan: In situ measurements by microelectrodes and planar optodes. Deep Sea Research Part I: Oceanographic Research Papers, Vol.52, No.10, (October 2005), pp. 1974-1987, ISSN 0967-0637

Hadas, R. \& Okon, Y. (1987). Effect of Azospirillum brasilense inoculation on root morphology and respiration in tomato seedlings. Biology and Fertility of Soils, Vol.5, No.3, (December 1987), pp. 241-247, ISSN 0178-2762

Hejl, A.M. \& Koster, K.L. (2004). Juglone disrupts root plasma membrane $\mathrm{H}^{+}$-ATPase activity and impairs water uptake, root respiration and growth in soybean (Glycine max.) and corn (Zea mays). Journal of Chemical Ecology, Vol.30, No.2, (February 2004), pp. 453-471, ISSN 0098-0331

Holst, G. \& Grunwald, B. (2001). Luminescence lifetime imaging with transparent oxygen optodes. Sensors and Actuators B, Vol.74, No.1-3, (April 2001), pp. 78-90, ISSN 0925-4005

Holst, G., Kohls, O., Klimant, I., König, B., Kühl, M. \& Richter, T. (1998). A modular luminescence lifetime imaging system for mapping oxygen distribution in biological samples. Sens. Actuators B, Vol.51, No.1-3, (August 1998), pp. 163-170, ISSN 0925-4005

Klimant, I., Meyer, V. \& Kühl, M. (1995). Fiber-optic oxygen microsensors, a new tool in aquatic biology. Limnology and Oceanography, Vol.40, No.6, (May 1995), pp. 11591165, ISSN 1541-5856

Kok, B. (1949). On the interrelation of respiration and photosynthesis in green plants. Biochimica et Biophysica Acta, Vol.3, No.1, (January 1949), pp. 625-631, ISSN 00052728

Kühl, M. \& Polerecky, L. (2008). Functional and structural imaging of phototrophic microbial communities and symbioses. Aquatic Microbial Ecology, Vol.53, No.1, (September 2008), pp. 99-118, ISSN 0948-3055

Kurimoto, K., Day, D.A., Lambers, H. \& Noguchi, K. (2004). Effect of respiratory homeostasis on plant growth in cultivars of wheat and rice. Plant Cell and Environment, Vol.27, No.7, (July 2004), pp. 853-862, ISSN 0140-7791

Liebsch, G., Klimant, I., Frank, B., Holst, G. \& Wolfbeis, O.S. (2000). Luminescence lifetime imaging of oxygen, $\mathrm{pH}$, and carbon dioxide distribution using optical sensors. Applied Spectroscopy, Vol. 54, No.4, (April 2000), pp. 548-559, ISSN 0003-7028

Loveys, B.R., Atkinson, L.J., Sherlock, D.J., Roberts, R.L., Fitter, A.H. \& Atkin, O.K. (2003). Thermal acclimation of leaf and root respiration: an investigation comparing inherently fast- and slow- growing plant species. Global Change Biology, Vol.9, No.6, (June 2003), pp. 895-910, ISSN 1365-2486 
Millar, A.H., Atkin, O.K., Menz, R.I., Henry, B., Faquhar, G. \& Day, D.A. (1998). Analysis of respiratory chain regulation in roots of soybean seedlings. Plant Physiology, Vol.117, No.3, (July 1998), pp. 1083-1093, ISSN 0032-0889

Penuelas, J., Murillo, J. \& Azcon-Bieto, J. (1988). Actual and potential dark respiration rates and different electron transport pathways in freshwater aquatic plants. Aquatic Botany, Vol.30, No.4, (May 1988), pp. 353-362, ISSN 0304-3770

Revsbech, N.P. \& Jørgensen, B.B. (1986). Microelectrodes: their use in microbial ecology. In: Advances in Microbial Ecology, Vol.9, K.C. Marshall (ed.), pp. 293-352, Springer , ISBN 0306421844 , New York, USA

Rolletschek, H., Stangelmayer, A. \& Borisjuk, L. (2009). The methodology and significance of microsensor-based oxygen mapping in plant seeds - an overview. Sensors, Vol.9, No.5, (April 2009), pp. 3218-3227, ISSN 1424-8220

Schröder, C. R., Neurauter, G. \& Klimant, I. (2007). Luminescent dual sensor for timeresolved imaging of $\mathrm{p} \mathrm{CO}_{2}$ and $\mathrm{p}_{2}$ in aquatic systems. Microchimica Acta, Vol.158, No.3-4, (May 2007), pp. 205-218, ISSN 0026-3672

Smith, E.L. (1937). The influence of light and carbon dioxide on photosynthesis. The Journal of General Physiology., Vol.20, No.6, (July 1937), pp. 807-830, ISSN 0022-1295

Tschiersch, H., Borisjuk, L., Rutten, T. \& Rolletschek, H. (2011). Gradients of seed photosynthesis and its role for oxygen balancing. Biosystems, Vol.103, No.2, (February 2011), pp. 302-308, ISSN 0303-2647

Van, T.K., Haller, W.T. \& Bowes, G. (1976). Comparison of photosynthetic characteristics of three submersed aquatic plants. Plant Physiology, Vol.58, No.6, (December 1976), pp. 761-768, ISSN 0032-0889

Volkmer, E., Drosse, I., Otto, S., Stangelmayer, A., Stengele, M., Cherian Kallukalam, B. \& Mutschler, W. (2008). Hypoxia in static and dynamic 3D culture systems for tissue engineering of bone. Tissue Engineering Part A, Vol.14, No.8, (August 2008), pp. 1331-1340, ISSN 2152-4947

Wang, X.D., Chen, X., Xie, Z.X. \& Wang X.R. (2008). Reversible optical sensor strip for oxygen. Angewandte Chemie, Vol.120, No.39, (September 2008), pp. 7560-7563, ISSN 1521-3757

Wang, X.D., Meier, R.J., Link, M. \& Wolfbeis, O.S. (2010). Photographing oxygen distribution. Angewandte Chemie International Edition, Vol.49, No.29, (July 2010), pp. 4907-4909, ISSN 1433-7851 


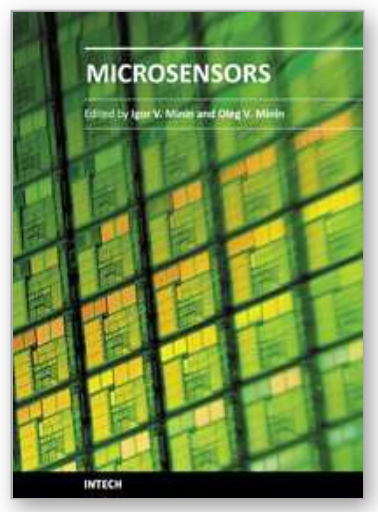

\author{
Microsensors \\ Edited by Prof. Igor Minin
}

ISBN 978-953-307-170-1

Hard cover, 294 pages

Publisher InTech

Published online 09, June, 2011

Published in print edition June, 2011

This book is planned to publish with an objective to provide a state-of-art reference book in the area of microsensors for engineers, scientists, applied physicists and post-graduate students. Also the aim of the book is the continuous and timely dissemination of new and innovative research and developments in microsensors. This reference book is a collection of 13 chapters characterized in 4 parts: magnetic sensors, chemical, optical microsensors and applications. This book provides an overview of resonant magnetic field microsensors based on MEMS, optical microsensors, the main design and fabrication problems of miniature sensors of physical, chemical and biochemical microsensors, chemical microsensors with ordered nanostructures, surfaceenhanced Raman scattering microsensors based on hybrid nanoparticles, etc. Several interesting applications area are also discusses in the book like MEMS gyroscopes for consumer and industrial applications, microsensors for non invasive imaging in experimental biology, a heat flux microsensor for direct measurements in plasma surface interactions and so on.

\title{
How to reference
}

In order to correctly reference this scholarly work, feel free to copy and paste the following:

Henning Tschiersch, Gregor Liebsch, Achim Stangelmayer, Ljudmilla Borisjuk and Hardy Rolletschek (2011). Planar Oxygen Sensors for Non Invasive Imaging in Experimental Biology, Microsensors, Prof. Igor Minin (Ed.), ISBN: 978-953-307-170-1, InTech, Available from:

http://www.intechopen.com/books/microsensors/planar-oxygen-sensors-for-non-invasive-imaging-inexperimental-biology

\section{INTECH}

open science | open minds

\section{InTech Europe}

University Campus STeP Ri

Slavka Krautzeka 83/A

51000 Rijeka, Croatia

Phone: +385 (51) 770447

Fax: +385 (51) 686166

www.intechopen.com

\section{InTech China}

Unit 405, Office Block, Hotel Equatorial Shanghai

No.65, Yan An Road (West), Shanghai, 200040, China 中国上海市延安西路65号上海国际贵都大饭店办公楼 405 单元

Phone: +86-21-62489820

Fax: $+86-21-62489821$ 
(C) 2011 The Author(s). Licensee IntechOpen. This chapter is distributed under the terms of the Creative Commons Attribution-NonCommercialShareAlike-3.0 License, which permits use, distribution and reproduction for non-commercial purposes, provided the original is properly cited and derivative works building on this content are distributed under the same license. 